\title{
Small colony variants have a major role in stability and persistence of Staphylococcus aureus biofilms
}

\author{
Zulfiqar Ali Mirani ${ }^{1}$, Mubashir Aziz ${ }^{2}$ and Seema Ismat Khan ${ }^{1}$
}

The present study was conducted to investigate the significance of small colony variants (SCVs) in biofilm life cycle of methicillin-resistant Staphylococcus aureus (MRSA) and methicillin-susceptible S. aureus (MSSA). All of these MRSA and MSSA isolates were recovered from different food commodities. Molecular typing showed that 21 MRSA isolates carry SCCmecA type IV and belong to agr type II. Out of 15 MSSA isolates, 7 were found to carry agr type II, 5 agr type I and 2 agr type III. All of the MRSA isolates studied adopted biofilm mode of growth after exposure to sublethal doses of oxacillin. MSSA isolates, on the other hand, were biofilm producers by nature, that is, without exposure to any stress. The biomass of the biofilm reaches its maximum thickness after $48 \mathrm{~h}$ of incubation at $35^{\circ} \mathrm{C}$. It was noticed that biofilm population consists of wild type and SCVs. Moreover, the number of SCVs increases with the age of biofilm. The SCVs of MRSA were unable to readopt biofilm mode of growth independently, irrespective of the presence or absence of oxacillin. The SCVs of MSSA, on the other hand, quickly revert to normal life just after a single subculture and show biofilm formation without any stress. Molecular studies showed a parallel reduction in the expression of the genes $i c a A, \operatorname{sig} \beta$ and $\operatorname{sar} A$, and also in the extracellular matrix production in SCVs of MRSA. This might be due to oxacillin as it seems to be a stress factor responsible for induction of biofilm formation in MRSA isolates. Contrary to the wild type, SCVs are metabolically inactive and do not respond to oxacillin, which is only active against the growing cells. Therefore, stress-responsive genes, that is, sig $\beta$ and $\operatorname{sar} A$, are not induced. Conversely, MSSA isolates are natural biofilm producers without induction through any known factors.

The Journal of Antibiotics (2015) 68, 98-105; doi:10.1038/ja.2014.115; published online 27 August 2014

\section{INTRODUCTION}

Staphylococcus aureus is a Gram-positive, nonmotile and nonsporeforming bacterium, which is well known to cause chronic infections. It persists on medical implants or host tissues owing to its ability to adhere to many types of surfaces and to adopt a biofilm mode of growth. ${ }^{1-3}$ The biofilm matrix is defined as a polymeric material that holds the community of bacterial cells together on a surface. Staphylococcal biofilm life cycle begins with the initial attachment of cells to the surface, followed by an intermediate state where the irreversibly attached cells form small aggregates, often referred to as microcolonies. Under optimal growth conditions, the microcolonies mature into an established biofilm that displays all the properties that are typically attributed to these structures. ${ }^{4}$ Once a biofilm is formed, significant heterogeneity develops at the molecular level, over $60 \%$ of the total cells become phenotypic variants. ${ }^{5} \mathrm{~A}$ lot of research is being carried out on the dormant, nondividing cells tolerant to antibiotics called "persister cells" that are formed during biofilm maturation, particularly small colony variants (SCVs) of S. aureus, a persistent and dormant cell type. ${ }^{6} \mathrm{SCV}$ are slow-growing cells, often isolated from clinical infections, with reduced metabolism and are highly resistant to antibiotics. ${ }^{7}$ One important characteristic that distinguishes SCVs from normal S. aureus isolates is their small colony size when grown on conventional agar plates with decreased pigmentation. ${ }^{8}$ The relationship between $S$. aureus SCVs and biofilm phenotype is unclear, but the characteristics shared by them suggest that they may have a similar underlying physiology. Both are slow growing and are resistant to antimicrobials. ${ }^{9}$ S. aureus biofilm formation is under the control of icaADBC-encoded enzymes and staphylococcal accessory regulator (sarA) and sig $\beta .{ }^{10}$ According to O'Neill et al., ${ }^{11}$ mutation of ica locus and sarA global regulator abolish biofilm formation in S. aureus. Similarly, Valle et al. ${ }^{12}$ reported that mutation in $\operatorname{sig} \beta$ also results in decreased expression of ica operon. In the present study, we have examined the role of $\operatorname{sig} \beta$, sar $A$ and ica in the biofilm formation processes of methicillin-resistant $S$. aureus (MRSA) and methicillinsusceptible $S$. aureus (MSSA) isolates. This study focused on the generation of SCVs during biofilm formation processes, reversion to wild type, and readoption of biofilm life cycle.

\section{MATERIALS AND METHODS}

Identification of $S$. aureus

During the study, a total of 36 biofilm-producing isolates of $S$. aureus, recovered from different food commodities, have been studied. For isolation

${ }^{1}$ Microbiological Analytical Centre Pakistan Council of Scientific and Industrial Research Laboratories Complex, Karachi, Pakistan and ${ }^{2}$ Department of Microbiology, Faculty of Veterinary Science, Bahauddin Zakariya University, Multan, Pakistan

Correspondence: Dr ZA Mirani, Microbiological Analytical Centre, Pakistan Council of Scientific and Industrial Research Laboratories Complex, Shahrah-e-Dr Salimuzzaman Siddiqui, Karachi 75280, Pakistan.

E-mail: mirani_mrsa@yahoo.com

Received 19 February 2014; revised 2 June 2014; accepted 22 July 2014; published online 27 August 2014 
and identification of $S$. aureus, the growth was monitored on differential and selective media such as Manitol Salt Agar (BioM, Durham, NC, USA), Staphchromo agar (Merck, Darmstadt, Germany), Staphylococcus 110 Agar (BioM), Baird-Parker Agar (Oxoid, Basingstoke, UK), DNase Agar (Merck) and Blood Agar (Oxoid). Staph Latex kit (Prolex Latex Agglutination System, Pro-Lab Diagnostics, South Wirral, UK) was used for confirmation.

\section{Phenotypic characterization of slime-producing bacteria}

Biofilm formation was initially confirmed by Congo red agar method as described earlier. ${ }^{13}$ Briefly, Brain Heart Infusion (BHI) agar plates containing $50 \mathrm{gl}^{-1}$ sucrose and $0.8 \mathrm{gl}^{-1}$ Congo red were prepared and streaked with strains and incubated aerobically for $24-48 \mathrm{~h}$ at $37^{\circ} \mathrm{C}$. Positive results were indicated by black colonies with dry crystalline appearance. Weak slime producers usually remained pink, although occasional darkening at the center of colonies was observed.

\section{Biofilm assay}

A qualitative assessment of biofilm formation on glass slides was evaluated as described earlier by Mirani and Jamil. ${ }^{14}$

\section{Scanning electron microscopy}

Scanning electron microcopy was used to analyze the production of extracellular matrix material after exposure to oxacillin. Biofilm slides were divided into $4 \mathrm{~mm}$ sections and washed with distilled water to remove the debris and were negatively stained with $2 \%$ uranyl acetate for $30 \mathrm{~s}$. These $4-\mathrm{mm}$ slide sections showed the presence of biofilm material when examined directly in a JOEL-JEM11 Electron Microscope (JEOL, Peabody, MA, USA).

\section{Evaluation of colony variance during $S$. aureus biofilm} development and detection of persister cells

The emergence of colony variants associated with biofilms of S. aureus was studied and these variants were enumerated, as described by Allegrucci and Sauer. ${ }^{15}$ Biofilm biomass was harvested from a glass slide, resuspended in saline (total volume of $1 \mathrm{ml}$ ), homogenized for $30 \mathrm{~s}$ to disrupt cell clusters by vigorous shaking, serially diluted and plated on tryptic soy agar and BairdParker agar plates. For the determination of stability of the colony variants, well-isolated colonies were subcultured on tryptic soy agar and Baird-Parker agar and incubated for $24 \mathrm{~h}$. This was repeated six times, and reversion with respect to colony size and biochemical reactions was monitored as described by Bayston et al. ${ }^{16}$ The cells surviving the highest concentration of oxacillin were picked and streaked on blood agar plates. These survivors were grown overnight in $5 \mathrm{ml}$ tryptic soy broth at $35^{\circ} \mathrm{C}$ and were subjected to oxacillin lethal dose again. The experiments were performed in duplicate. The persister cells obtained were characterized for stability, hemolysis, catalase production, clumping factor, coagulase production and DNase production by using the method of Bayston et al. ${ }^{16}$ The drop plate method described by Chen et al. ${ }^{17}$ was followed to count CFUs. Determination of MIC of planktonic bacteria

The MIC of oxacillin was determined against bacteria that were shed from the glass slides as described before. ${ }^{18}$

\section{Minimum biofilm inhibitory concentration assay}

Methods described by Merle et al. ${ }^{19}$ and Mahami et al..$^{18}$ were employed for MIC evaluation of biofilms. Slides with attached bacterial biofilm were washed with normal saline to remove the debris and loosely attached cells, and were transferred into $50 \mathrm{ml}$ tubes containing diluted oxacillin as $8-56 \mu \mathrm{g} \mathrm{ml}^{-1}$ and incubated for $24 \mathrm{~h}$ at $35^{\circ} \mathrm{C}$. The slide was then removed, rinsed in sterile physiological saline $(0.85 \% \mathrm{NaCl})$ and placed in another tube containing fresh, sterile $1 \%$ peptone water. The remaining biofilm was removed from the slide by vigorous vortexing for $10 \mathrm{~min}$. This tube was incubated for $24 \mathrm{~h}$ at $35^{\circ} \mathrm{C}$. The presence of viable bacteria was determined by the pour plate method. Growth of bacteria in a particular tube indicated the regrowth of planktonic bacteria detached from biofilm.

\section{PCR}

For molecular studies, genomic DNA was isolated using the DNase Kit (Qiagen, Hilden, Germany), following the manufacturer's instructions. PCR

Table 1 Density of normal and persister cells in the biofilms of MRSA at 24,48 and $96 \mathrm{~h}$ of incubation at $35^{\circ} \mathrm{C}$ in the presence of sublethal doses of oxacillin

\begin{tabular}{|c|c|c|c|c|c|c|c|c|c|c|c|c|c|c|}
\hline \multirow[b]{2}{*}{ S\# } & \multirow[b]{2}{*}{$\begin{array}{l}\text { MIC } \\
\left(\mu g m I^{-1}\right)\end{array}$} & \multirow[b]{2}{*}{$\begin{array}{c}\text { SCCmecA } \\
\text { type }\end{array}$} & \multirow[b]{2}{*}{$\begin{array}{l}\text { Agr } \\
\text { type }\end{array}$} & \multicolumn{3}{|c|}{$24 h$} & \multicolumn{5}{|c|}{$48 h$} & \multicolumn{3}{|c|}{$96 h$} \\
\hline & & & & $\begin{array}{c}\text { Biofilm } \\
\text { OD }\end{array}$ & $\begin{array}{l}\text { Normal } \\
\text { cells }\end{array}$ & $\begin{array}{c}\text { Persister } \\
\text { cells }\end{array}$ & $\begin{array}{c}\text { Biofilm } \\
\text { OD }\end{array}$ & $\begin{array}{l}\text { Biofilm MIC } \\
\text { in }\left(\mu g \mathrm{ml}^{-1}\right)\end{array}$ & $\begin{array}{l}\text { Normal } \\
\text { cells }\end{array}$ & $\begin{array}{c}\text { Persister } \\
\text { cells }\end{array}$ & $\begin{array}{l}\text { Persister cells } \\
M I C\left(\mu g I^{-1}\right)\end{array}$ & $\begin{array}{c}\text { Biofilm } \\
\text { OD }\end{array}$ & $\begin{array}{l}\text { Normal } \\
\text { cells }\end{array}$ & $\begin{array}{c}\text { Persister } \\
\text { cells }\end{array}$ \\
\hline 1. & 64 & IV & ॥ & 0.09 & $1 \times 10^{2}$ & 00 & 0.96 & 128 & $1 \times 10^{6}$ & $1 \times 10^{2}$ & 128 & 0.23 & $1 \times 10^{3}$ & $1 \times 10^{3}$ \\
\hline 2. & 64 & IV & II & 0.08 & $1 \times 10^{2}$ & 00 & 0.92 & 128 & $1 \times 10^{6}$ & $1 \times 10^{3}$ & 128 & 0.43 & $1 \times 10^{4}$ & $1 \times 10^{3}$ \\
\hline 3. & 64 & IV & II & 0.23 & $1 \times 10^{2}$ & 00 & 0.89 & 128 & $1 \times 10^{5}$ & $1 \times 10^{2}$ & 64 & 0.51 & $1 \times 10^{4}$ & $1 \times 10^{4}$ \\
\hline 4. & 64 & IV & II & 0.27 & $1 \times 10^{2}$ & 00 & 0.73 & 128 & $1 \times 10^{5}$ & $1 \times 10^{3}$ & 128 & 0.52 & $1 \times 10^{3}$ & $1 \times 10^{4}$ \\
\hline 5. & 32 & IV & II & 0.17 & $1 \times 10^{2}$ & 00 & 0.86 & 128 & $1 \times 10^{5}$ & $1 \times 10^{2}$ & 64 & 0.41 & $1 \times 10^{4}$ & $1 \times 10^{3}$ \\
\hline 6. & 32 & IV & II & 0.21 & $1 \times 10^{2}$ & 00 & 0.80 & 128 & $1 \times 10^{5}$ & $1 \times 10^{3}$ & 128 & 0.23 & $1 \times 10^{3}$ & $1 \times 10^{3}$ \\
\hline 7. & 32 & IV & II & 0.22 & $1 \times 10^{2}$ & 00 & 0.79 & 128 & $1 \times 10^{5}$ & $1 \times 10^{3}$ & 128 & 0.21 & $1 \times 10^{3}$ & $1 \times 10^{3}$ \\
\hline 8. & 32 & IV & II & 0.35 & $1 \times 10^{2}$ & 00 & 0.76 & 128 & $1 \times 10^{5}$ & $1 \times 10^{3}$ & 128 & 0.11 & $1 \times 10^{2}$ & $1 \times 10^{1}$ \\
\hline 9. & 32 & IV & II & 0.33 & $1 \times 10^{2}$ & 00 & 0.75 & 128 & $1 \times 10^{5}$ & $1 \times 10^{3}$ & 128 & 0.13 & $1 \times 10^{2}$ & $1 \times 10^{1}$ \\
\hline 10. & 16 & IV & II & 0.55 & $1 \times 10^{3}$ & 00 & 0.87 & 128 & $1 \times 10^{5}$ & $1 \times 10^{2}$ & 64 & 0.33 & $1 \times 10^{3}$ & $1 \times 10^{2}$ \\
\hline 11. & 16 & IV & II & 0.54 & $1 \times 10^{3}$ & 00 & 0.81 & 64 & $1 \times 10^{5}$ & $1 \times 10^{3}$ & 64 & 0.27 & $1 \times 10^{3}$ & $1 \times 10^{2}$ \\
\hline 12. & 08 & IV & II & 0.55 & $1 \times 10^{3}$ & 00 & 0.86 & 64 & $1 \times 10^{5}$ & $1 \times 10^{2}$ & 64 & 0.37 & $1 \times 10^{2}$ & $1 \times 10^{2}$ \\
\hline 13. & 08 & IV & II & 0.25 & $1 \times 10^{2}$ & 00 & 0.81 & 64 & $1 \times 10^{5}$ & $1 \times 10^{3}$ & 32 & 0.22 & $1 \times 10^{2}$ & $1 \times 10^{2}$ \\
\hline 14. & 64 & IV & II & 0.09 & $1 \times 10^{2}$ & 00 & 0.85 & 192 & $1 \times 10^{6}$ & $1 \times 10^{2}$ & 128 & 0.23 & $1 \times 10^{3}$ & $1 \times 10^{3}$ \\
\hline 15. & 64 & IV & 11 & 0.08 & $1 \times 10^{2}$ & 00 & 0.97 & 256 & $1 \times 10^{6}$ & $1 \times 10^{3}$ & 192 & 0.43 & $1 \times 10^{4}$ & $1 \times 10^{3}$ \\
\hline 16. & 32 & IV & II & 0.23 & $1 \times 10^{2}$ & 00 & 0.82 & 256 & $1 \times 10^{5}$ & $1 \times 10^{3}$ & 192 & 0.51 & $1 \times 10^{3}$ & $1 \times 10^{4}$ \\
\hline 17. & 32 & IV & 11 & 0.27 & $1 \times 10^{2}$ & 00 & 0.79 & 256 & $1 \times 10^{5}$ & $1 \times 10^{3}$ & 128 & 0.52 & $1 \times 10^{3}$ & $1 \times 10^{4}$ \\
\hline 18. & 16 & IV & II & 0.17 & $1 \times 10^{2}$ & 00 & 0.81 & 128 & $1 \times 10^{5}$ & $1 \times 10^{2}$ & 64 & 0.41 & $1 \times 10^{4}$ & $1 \times 10^{3}$ \\
\hline 19. & 16 & IV & II & 0.21 & $1 \times 10^{2}$ & 00 & 0.83 & 64 & $1 \times 10^{5}$ & $1 \times 10^{2}$ & 64 & 0.23 & $1 \times 10^{3}$ & $1 \times 10^{3}$ \\
\hline 20. & 08 & IV & II & 0.22 & $1 \times 10^{2}$ & 00 & 0.76 & 128 & $1 \times 10^{5}$ & $1 \times 10^{3}$ & 128 & 0.21 & $1 \times 10^{3}$ & $1 \times 10^{3}$ \\
\hline 21. & 08 & IV & II & 0.35 & $1 \times 10^{2}$ & 00 & 0.72 & 64 & $1 \times 10^{5}$ & $1 \times 10^{2}$ & 64 & 0.11 & $1 \times 10^{2}$ & $1 \times 10^{1}$ \\
\hline
\end{tabular}

Differences in oxacillin MICs of normal cells, persister cells and biofilms checked after $48 \mathrm{~h}$ of incubation have also been mentioned in addition to molecular typing of subject isolates. 
Table 2 Density of normal and persister cells in the biofilms of MSSA recorded after 24,48 and $96 \mathrm{~h}$ of incubation at $35{ }^{\circ} \mathrm{C}$ in the presence of sublethal doses of oxacillin

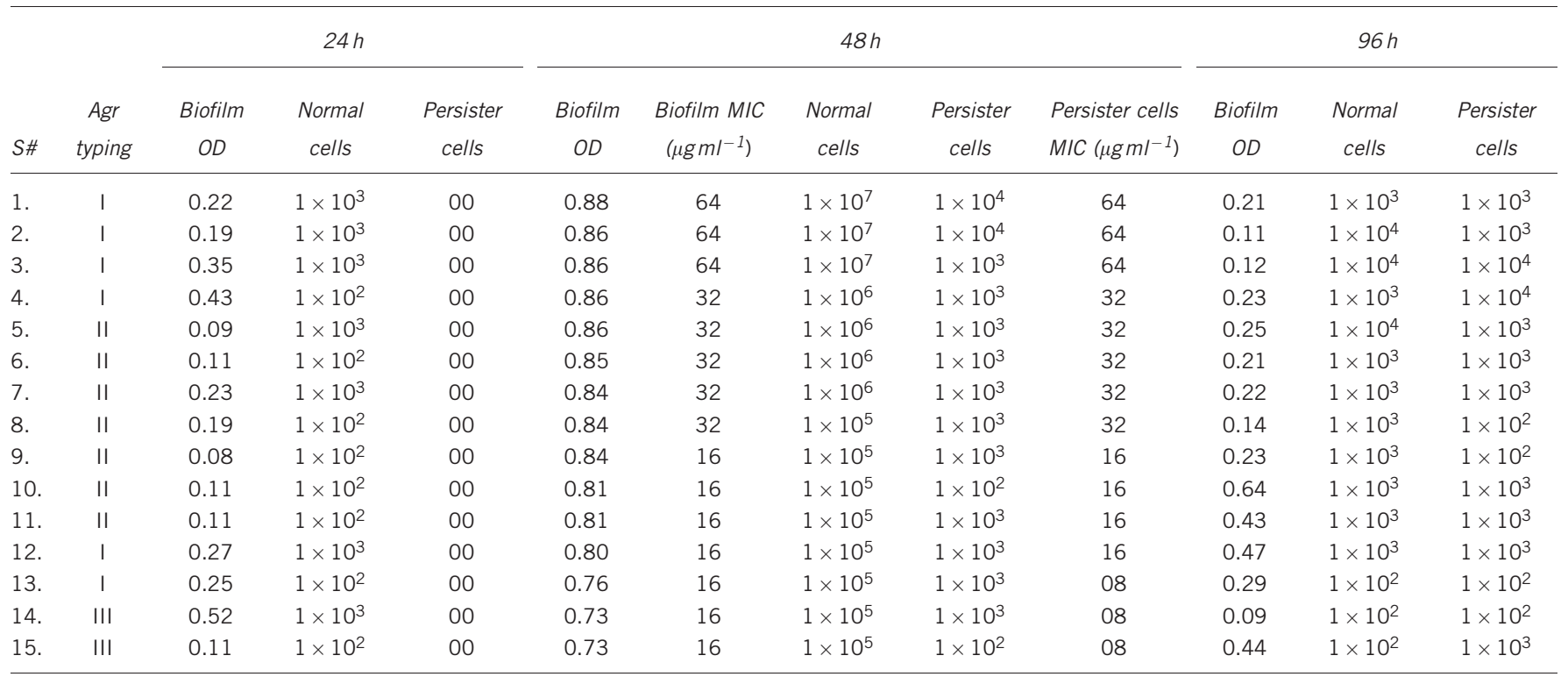

Differences in oxacillin MICs of normal cells, persister cells and biofilm checked after $48 \mathrm{~h}$ of incubation have also been mentioned.

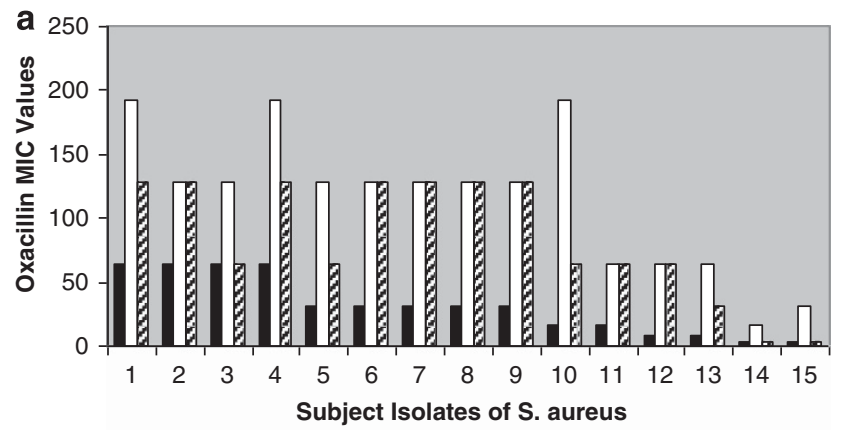

- Original Oxacillin MIC of Isolate $\square$ Oxacillin MIC of Biofilms Oxacillin MIC of Persister Cells

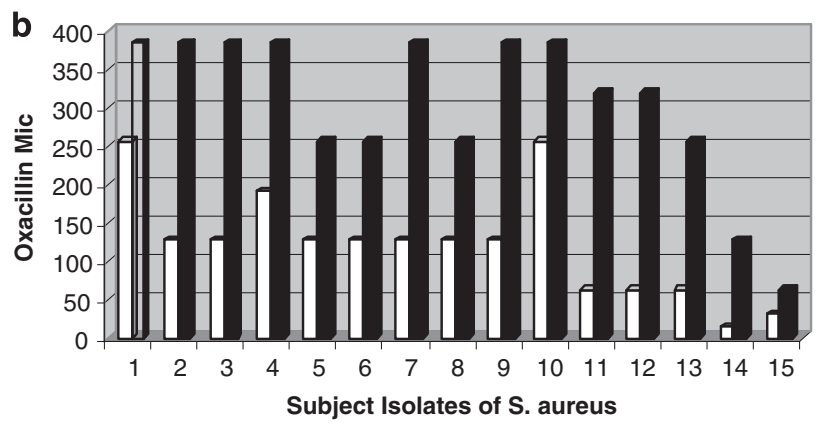

$\square$ MIC of Biofilms at 48h $\quad$ MIC of Biofilms at $96 \mathrm{~h}$

Figure 1 (a) Comparison of oxacillin susceptibility pattern of $S$. aureus, biofilm produced by the subject isolates and persister cells recovered from biofilm consortia after $48 \mathrm{~h}$ of incubation at $35^{\circ} \mathrm{C}$. (b) Comparison of oxacillin susceptibility pattern of biofilms of subject isolates at 48 and $96 \mathrm{~h}$ of incubation.

amplification of icaA and mecA genes was performed with an MWG Thermal Cycler (MWG-Biotech, Ebensburg, Germany) in a volume of $50 \mu \mathrm{l}$ of Promega MASTER Mix (Madison, WI, USA). Primers and conditions for the expression of icaA and mecA were used as described previously by Nuryastuti et al. ${ }^{20}$ and

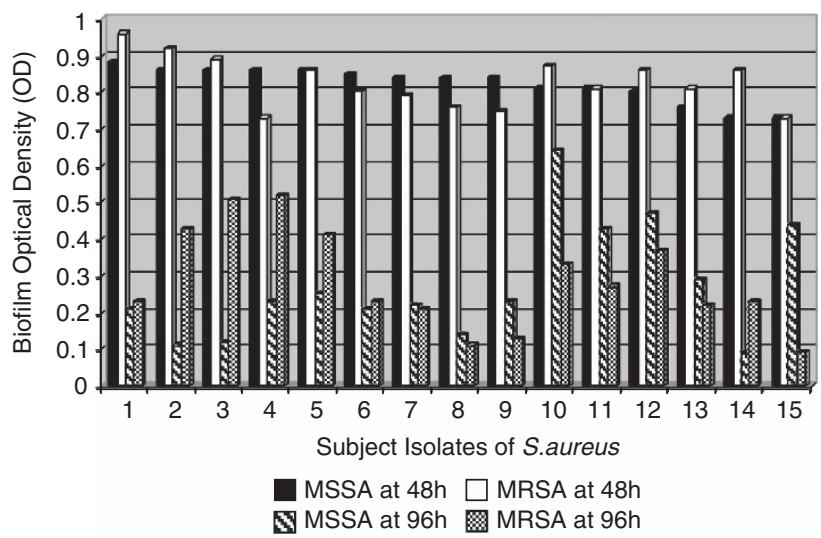

Figure 2 Biofilm formation by MRSA isolate after exposure to sublethal doses of oxacillin and MSSA isolates without any stress in terms of OD.

Black et al., ${ }^{21}$ and the primers published earlier ${ }^{22,23}$ were used for sig $\beta$ and sar $A$ expression study. 16S RNA was used as an internal control for gene expression and species identification as described by Shang $e$ et al. ${ }^{24}$ The agr allele types (IIV) were determined by multiplex PCR using the agr group-specific primers and amplification conditions described by Gilot et al. ${ }^{10}$ and Xie et al. ${ }^{25}$ For real-time reverse transcription PCR studies, total RNA was extracted from the cell pellet using TRIzol (Invitrogen, Carlsbad, CA, USA) followed by RQ1 RNase-free DNase (Promega) treatment for elimination of any remaining DNA. A real-time reverse transcription PCR was performed. The gene expression level of $\operatorname{sar} A, \operatorname{sig} \beta, i c a A$ and mecA were visualized against the $16 \mathrm{~S}$ expression level.

\section{RESULTS}

In the present study, a total of 36 food-borne isolates of $S$. aureus were studied (Tables 1 and 2). Out of 36, 21 isolates were MRSA carrying $m e c A$ gene belonging to SCCmecA group IV and carrying agr type II and 15 were MSSA. Out of 15 MSSA isolates, 7 were found to carry agr type II, 5 carry agr type I and 2 isolates carry agr type III. These 


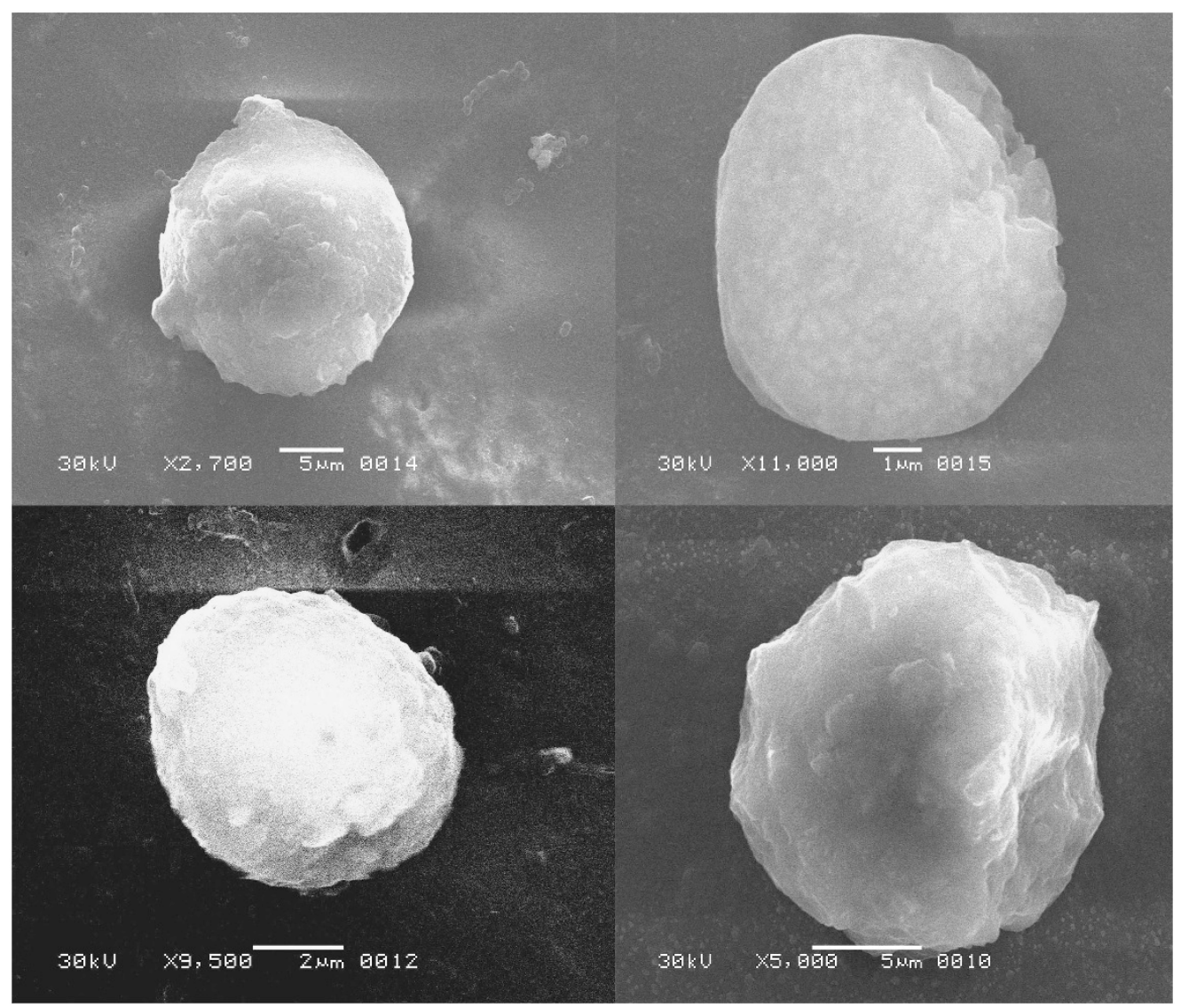

Figure 3 Scanning electron micrographs of SCV recovered from biofilm consortia of MRSA isolates, showing rough surface with variable morphology devoid of extracellular matrix.

isolates were identified as $S$. aureus on the basis of Gram staining, growth and colony morphology on Baird-Parker agar, reaction on DNase agar and were confirmed by $16 \mathrm{~S}$ ribosomal RNA. It was noticed that MRSA isolates adopted biofilm mode of growth after exposure to sublethal doses of oxacillin (Table 1 and Figures 1a and b), whereas all the MSSA isolates were natural biofilm producers without exposure to any stress (Table 2). The biomass of the biofilm reaches the maximum thickness after $48 \mathrm{~h}$ of incubation at $35^{\circ} \mathrm{C}$ (Figure 2). The biofilms showed a high proportion of heterogeneity; majority of the isolates showed typical colony formation after $24 \mathrm{~h}$, had the typical morphology of $S$. aureus, were hemolytic and coagulase positive along with some tiny slow-growing nonpigmented and nonhemolytic colonies that appeared after $48-72 \mathrm{~h}$ of incubation on tryptic soy agar plates (Tables 1 and 2). The number of these tiny nonpigmented colonies reaches almost $50 \%$ of the total population of biofilm consortium after $96 \mathrm{~h}$ of incubation (Tables 1 and 2). The SCVs recovered from the heterogeneous population of MRSA biofilm consortium had a slow growth rate and prolonged lag phase, and did not revert during $24 \mathrm{~h}$ of incubation (Table 1 and Figure 1). The MIC of oxacillin for SCVs was two- to fourfold higher than normal and revertant phenotypes (Tables 1 and 2). However, after providing proper in vitro growth conditions, such as enriched media without addition of antibiotic, these persister SCVs yielded wild-type colony morphology after two to three subculturing steps. Reexposure of revertant clones with sublethal doses of oxacillin resulted in the readoption of biofilm mode of growth at the same frequency as original wild-type population. Moreover, these persister cells of SCVs were unable to readopt biofilm mode of growth independently, either in the presence or in the absence of oxacillin. The MIC of biofilms was two- to fourfold higher at $48 \mathrm{~h}$ and six- to eightfold higher at $96 \mathrm{~h}$ than the values for normal and revertant phenotypes (Tables 1 and 2). However, no differences in the MICs of SCVs were noticed after 48 and $96 \mathrm{~h}$ of incubation. This seems to be associated with the loss of ability for extracellular matrix formation and inability to return to normal growth phenotypes. The OD of biofilm was highest at $48 \mathrm{~h}$, after that a reduction was noticed; however, the SCVs count was highest at $96 \mathrm{~h}$ of incubation (Tables 1 and 2). The reduction in biofilm OD and CFU is due to the increase in SCVs population. The SCVs are metabolically inactive hence they are unable to produce matrix material, which results in reduced OD and dispersion rate.

In this study, 15 MSSA isolates were tested to determine whether the SCVs are associated with oxacillin and MRSA only or whether they are a part of $S$. aureus biofilm life cycle. It was noticed that MSSA biofilms also harbor SCVs as MRSA (Table 2). Moreover, the SCVs of MSSA quickly revert to normal life just after a single subculture. Unlike MRSA, SCVs of MSSA isolates showed biofilm formation without any stress. Once these colony variants dominate the biofilm consortium, they are very difficult to disperse (Table 2). Moreover, scanning electron microscopy of SCVs of MRSA revealed the presence of heterogeneous bacteria of different sizes, with rough and dry surfaces devoid of extracellular matrix material or debris, which is a property of normal biofilm phenotypes (Figure 3). Most of the SCV cells seemed to have irregular shape and larger size than normal cells. Conversely, SCVs of MSSA showed smooth cells covered with some extracellular matrix material (Figure 4). Furthermore, the expression of icaA gene was decreased in all of the SCVs tested compared with 


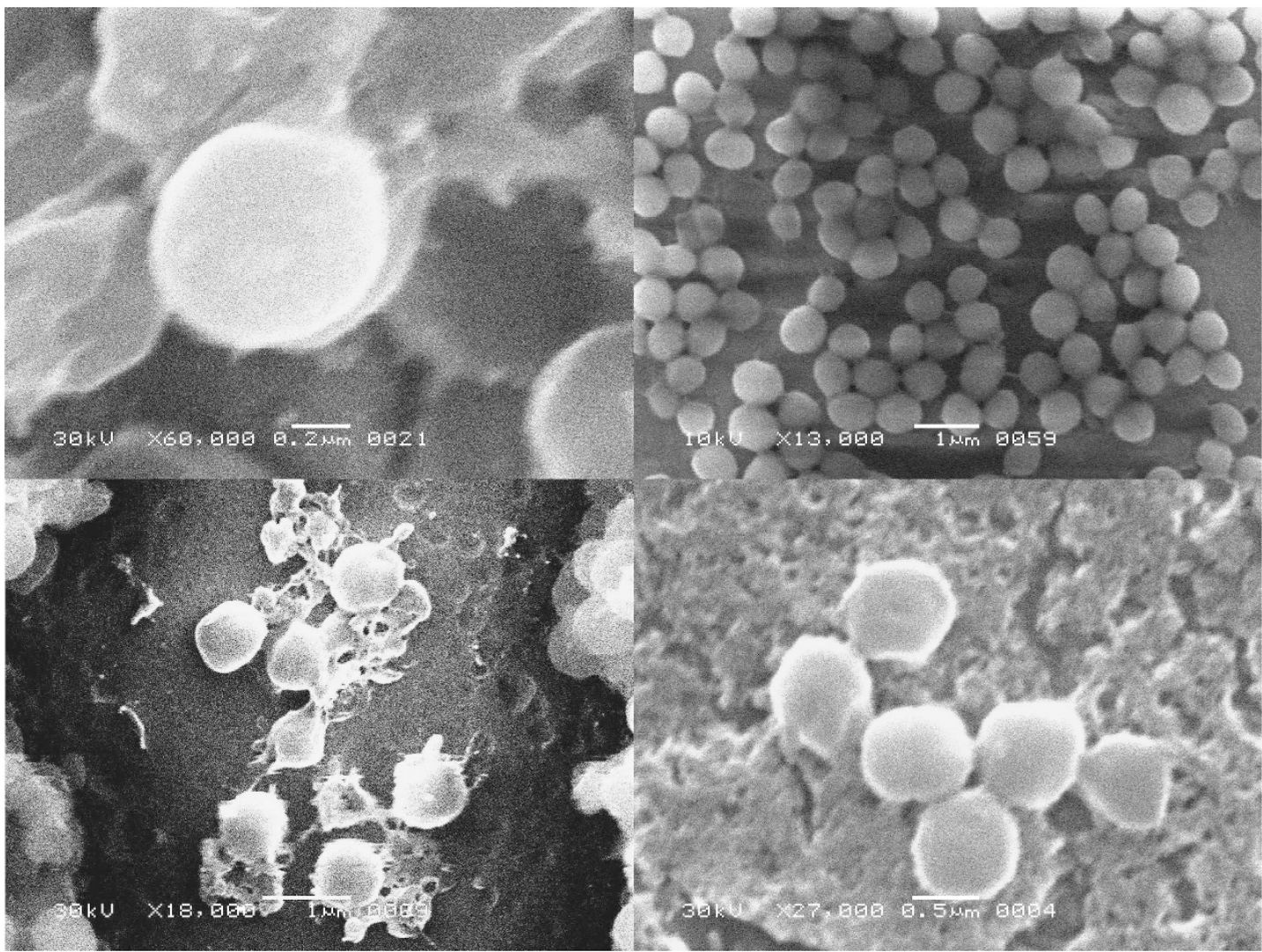

Figure 4 Scanning Electron Micrographs SCV recovered from biofilm consortia of MSSA isolates, smooth surface covered with extracellular matrix.

normal (wild-type) cells (Figure 5a). Similarly, mecA and $\operatorname{sig} \beta$ gene expression was decreased in SCVs as compared with wild type and planktonic cells recovered from biofilm consortia (Figure 5). However, mecA expression was increased in normal morphotypes recovered from biofilms as compared with wild type, and some isolates recovered from biofilm consortia, such as isolates 1, 8, 9, 10 and 11, showed an increased $\operatorname{mec} A$ expression (Figure 6). More pronounced variations were noticed in $\operatorname{sig} \beta$ expression, which reduced with incubation time (Figure 5). The SCVs recovered after $96 \mathrm{~h}$ of incubation showed a more reduced $\operatorname{sig} \beta$ expression as compared with $48 \mathrm{~h}$ of incubation (Figure 5). However, icaA studies showed a similar profile in MRSA isolates irrespective of the presence or absence of oxacillin, and SCVs recovered in both conditions were unable to adopt biofilm mode of growth. In MSSA isolates, no significant difference was noticed in gene expression of $\operatorname{sig} \beta$ (Figure $5 \mathrm{c}$ ). The normal (wild type) planktonic cells recovered from 48-h-old biofilm and SCVs showed almost identical results. However, the icaA expression was reduced in SCVs of MSSA isolates (Figure 7). It is noteworthy that the expression levels of $\operatorname{sig} \beta$ and ica $A$ were increased in the revertants of SCVs recovered from MRSA biofilms. However, no substantial differences were observed in biofilm-forming capability of revertants and wild-type MRSA isolates. Although the SCVs recovered from biofilm of MSSA isolates showed a significant decrease in expression of $i c a A$ gene, even then these were capable of biofilm formation like the wild type on glass slides. The other significant difference noticed in terms of sarA gene expression was that it was (Figure 8) a positive regulator of the agr operon and influences the regulation of various virulence factors in an agrdependent pathway. Therefore, it was speculated that sarA might affect biofilm formation indirectly through agr. A drastic reduction in
sarA (Figure 8) expression was noticed in SCVs of MRSA as compared with wild type. The planktonic isolates of MRSA grown in the presence of oxacillin showed the highest level of sarA expressionat $24-48 \mathrm{~h}$. This suggests that sarA expression is regulated by the presence of oxacillin, as MRSA isolates adopt biofilm mode of growth after exposure to oxacillin that also augment sarA expression. Comparative analysis of MRSA and MSSA isolates also confirmed the role of oxacillin in the regulation of sarA gene. Moreover, the reduction in sarA gene expression was also noticed in SCVs of MSSA although not as drastic as that in SCVs of MRSA. This reduction in the gene expression of $s a r A$ in SCVs of MSSA isolates might be due to arrested metabolism and slow growth rate. Like sig $\beta$, sarA gene seems to be active and responsible for the recovery of and readoption of biofilm life cycle in SCVs of MSSA isolates.

\section{DISCUSSION}

Bacteria in natural habitats commonly exist in a biofilm consortium, which is considered as a protective mode of living adopted by most of the bacteria to survive in callous environment. ${ }^{26-28}$ It has been reported that the total number of cells in an established biofilm is $\sim 10^{4}-10^{8} \mathrm{CFU} \mathrm{cm}^{-2}$; however, culturable bacteria represent only a small fraction of total cell numbers, usually $10^{1}-10^{6} \mathrm{CFU} \mathrm{cm}^{-2} \cdot{ }^{29}$ In a previous work conducted in our lab, it was noticed that the subinhibitory doses of oxacillin provoke biofilm formation in MRSA and a strong correlation was noticed in SCCmec type IV, agr type II and biofilm formation. ${ }^{30}$ Moreover, the heterogeneous MRSA isolates also exhibit heterogeneity in biofilm phenotype. This was confirmed by the mixed colonies,that is, pinkish (biofilm-negative) and black (biofilm-positive) colonies on Congo red agar plate. ${ }^{30}$ Further studies showed that the biofilms consortium also harbor 


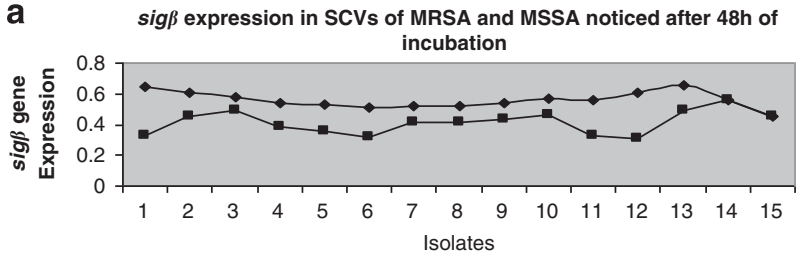

b
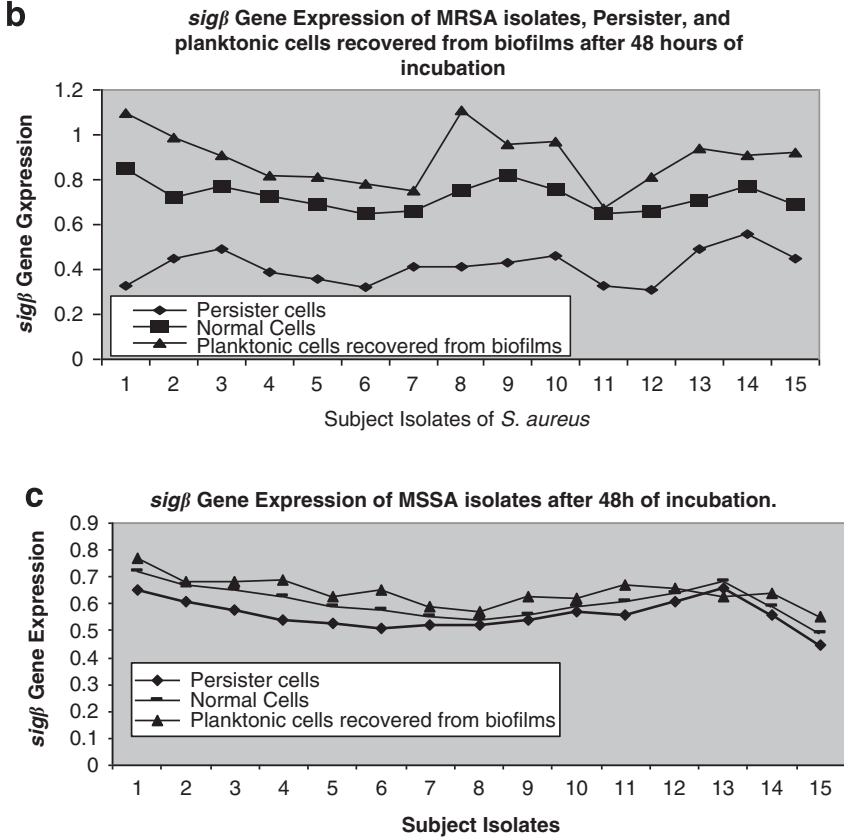

Figure 5 Comparison of $\operatorname{sig} \beta$ gene expression in normal cells, planktonic cells shed from biofilms and persister cells of MRSA recovered from biofilms after $48 \mathrm{~h}$ of incubation at $35^{\circ} \mathrm{C}$. Isolates No. 1 to 4 are MRSA (MIC $64 \mu \mathrm{g} \mathrm{ml}^{-1}$ ), 5 to 9 are MRSA (MIC $32 \mu \mathrm{g} \mathrm{ml}^{-1}$ ), 10 to 11 MRSA (MIC $16 \mu \mathrm{g} \mathrm{ml}^{-1}$ ), 12 to 13 are MRSA (MIC $8 \mu \mathrm{gml}^{-1}$ ), and 14 to 15 are MSSA (MIC $4 \mu \mathrm{g} \mathrm{ml}^{-1}$ ).

mecA Gene Expression of Persister, planktonic cells recovered from biofilms after 48 and subject isolates of MRSA after $24 \mathrm{~h}$ of incubation

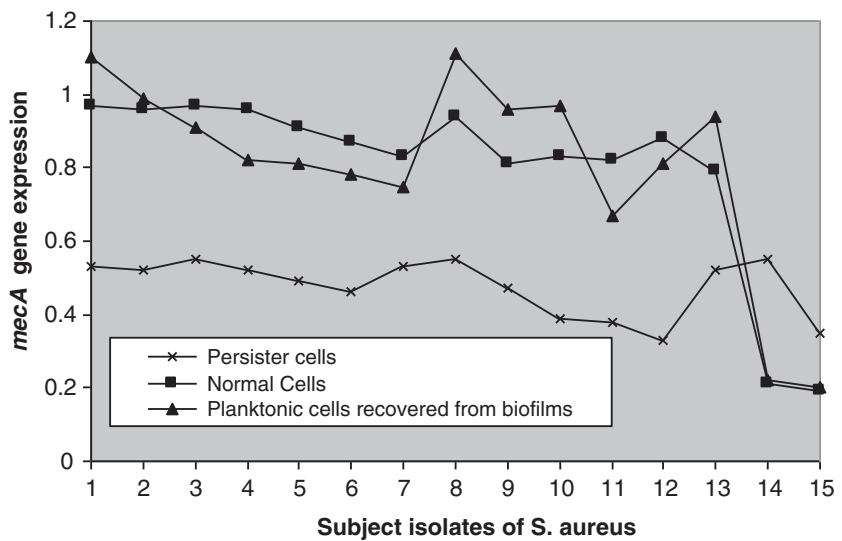

Figure 6 Comparison of $m e c A$ gene expression in subject isolates of MRSA.

heterogeneous population,for example, one group showed normal wild-type phenotype, whereas the other group was slow-growing, nonpigmented with reduced metabolism and high antibiotic resistance. This latter group was known as SCVs or persister cells.
icaA gene expression in planktonic cells of MRSA, MSSA and SCVs recovered after $48 \mathrm{~h}$ of incubation

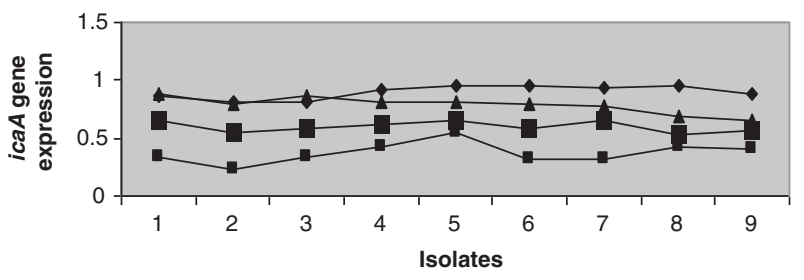

$\longrightarrow$ icaA in MRSA $\rightarrow$ ica in SCVs of MRSA

$\longrightarrow$ icaA in MSSA - ica in SCVs of MSSA

b

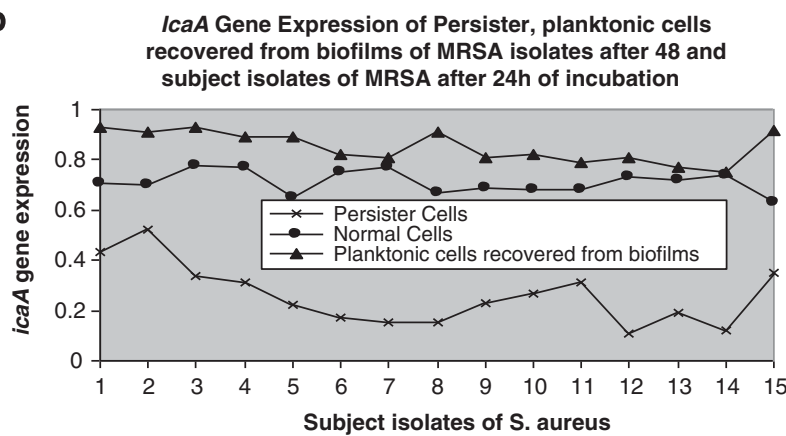

C

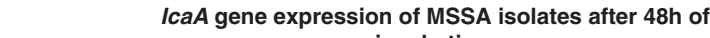
incubation

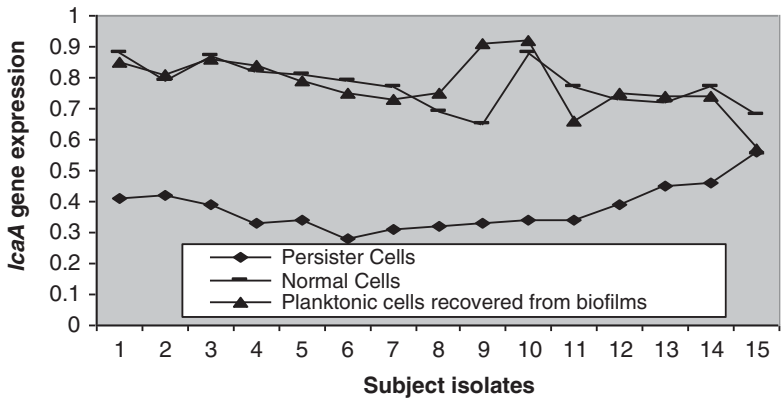

Figure 7 Comparison of ica gene expression in normal cells, planktonic cells shed from biofilms and persister cells of MRSA recovered from biofilms after $48 \mathrm{~h}$ of incubation at $35^{\circ} \mathrm{C}$. Isolates No. 1 to 4 are MRSA (MIC $64 \mu \mathrm{g} \mathrm{ml}^{-1}$ ), 5 to 9 are MRSA (MIC $32 \mu \mathrm{g} \mathrm{ml}^{-1}$ ), 10 to $11 \mathrm{MRSA}$ (MIC $16 \mu \mathrm{g} \mathrm{ml}^{-1}$ ), 12 to 13 are MRSA (MIC $8 \mu \mathrm{g} \mathrm{ml}-1$ ), and 14 to 15 are MSSA (MIC $4 \mu \mathrm{g} \mathrm{ml}^{-1}$ ).

These variants may represent a stable, inheritable change or a transient colony type. This was observed after the study of two groups of S. aureus. Group one consisting of MRSA isolates showed biofilm formation after exposure to subinhibitory doses of oxacillin, whereas group two consisted of biofilm-producing MSSA isolates. The SCVs were not observed in planktonic population in any of the isolates studied. This population seems to be associated with biofilm environment. At a point, when the biofilm reaches a critical mass, the outermost layer begins to shed away planktonic organisms. These organisms are now free to escape from the biofilm and to colonize other surfaces. Cells nearest to the surface become quiescent, as in case of SCVs, or die due to perfusion or lack of nutrients, decreased $\mathrm{pH}, \mathrm{pO}_{2}$ or accumulation of toxic metabolic by-products. ${ }^{31}$ Although the SCVs were detected in the dispersed population as well, the majority remained stuck to the surface. One of the important features of the present study is oxacillin resistance of all the isolates in biofilms and SCVs irrespective of their behavior in wild type. The SCVs recovered from biofilms of MRSA showed six- to eightfold higher MIC than wild type and similar character was observed in the SCVs of 
a

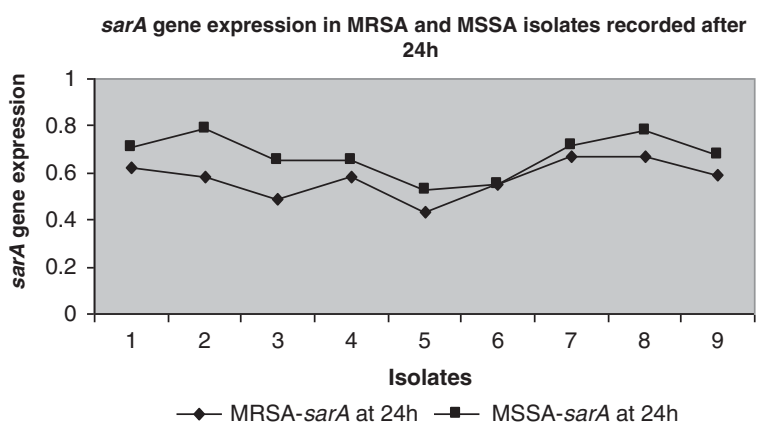

b

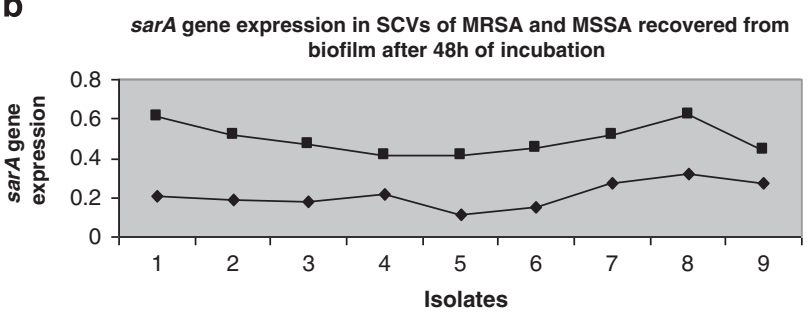

$\rightarrow$ SCVs of MRSA-sarA at 48h - SCVs of MSSA-sarA at $48 \mathrm{~h}$

C

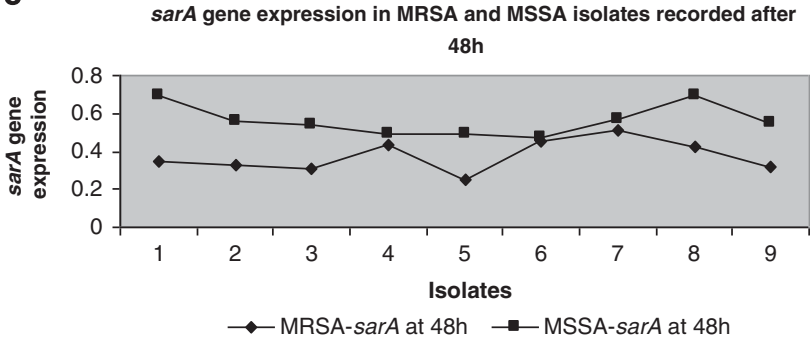

Figure 8 Comparison of sarA gene expression in normal cells, planktonic cells shed from biofilms and persister cells of MRSA recovered from biofilms after $48 \mathrm{~h}$ of incubation at $35^{\circ} \mathrm{C}$. Isolates No. 1 to 4 are MRSA (MIC $64 \mu \mathrm{gl}^{-1}$ ), 5 to 9 are MRSA (MIC $32 \mu \mathrm{g} \mathrm{ml}{ }^{-1}$ ), 10 to 11 are MRSA (MIC $16 \mu \mathrm{gml}^{-1}$ ), 12 to 13 are MRSA (MIC $8 \mu \mathrm{gml}^{-1}$ ), and 14 to 15 MSSA (MIC $4 \mu \mathrm{g} \mathrm{ml}^{-1}$ ).

MSSA. The MIC of biofilms also increases with the prevalence of SCVs' transient-resistant phenotypes. This is also supported by Singh et al. ${ }^{32}$ and Lewis. ${ }^{33}$ Several studies ${ }^{32-34}$ have reported that SCVs have increased biofilm-forming ability compared with the wild-type parental strain. On the contrary, the present study showed that SCVs recovered from biofilms of MRSA isolates were more stable and they are unable to adopt biofilm mode of growth independently, without the help of metabolically active population. However, once these colony variants dominate the biofilm population they stabilize it by hyperadherence and persist there for a long time in a dormant state. This was also supported by Latimer et al. ${ }^{35}$ On the other hand, the present research showed that SCVs of MSSA isolates quickly revert to the wild type and readopt biofilm mode of growth. This showed that at least two different mechanisms of biofilm formation exist in S. aureus. The first mechanism implies the production of the polysaccharide intercellular adhesion, which requires the ica gene cluster, whereas the second mechanism is ica independent. ${ }^{11}$ The ica-independent mechanism is controlled by sig $\beta$ and sarA. The major difference in our subject groups of SCVs is the induction of biofilm-associated gene expression, that is, ica, sig $\beta$ and sarA. A drastic reduction was noticed in ica, sig $\beta$ and sarA gene expression in SCVs of MRSA isolates, whereas planktonic (wild- type) and SCV phenotypes of MSSA showed very minor difference in terms of sig $\beta$ and sarA gene expression. It seems that, SCVs of MSSA use an ica-independent pathway for biofilm formation. This is confirmed by the diminished expression of ica gene.

According to Beenken et al. ${ }^{36}$ and Rachid et al., ${ }^{37} \operatorname{sig} \beta$ is responsible for biofilm formation in $S$. aureus. This is also supported by Kiedrowski et al. ${ }^{38}$ and Mitchell et al., ${ }^{39}$ who suggested that the activation of $\operatorname{sig} \beta$ is necessary for generation of SCVs and biofilm formation. Recently, Lauderdale et al. ${ }^{40}$ have shown that $\operatorname{sig} \beta$ is an essential regulator of the ica-independent biofilm formation and suggested that $\operatorname{sig} \beta$ acts upstream of the agr system, allowing the formation of biofilm to be regulated as a function of environmental factors. In addition to $\operatorname{sig} \beta$, the staphylococcal accessory regulator sar $A$, is also a central regulatory element that controls the $S$. aureus virulence factors. ${ }^{12}$ Valle et al. ${ }^{12}$ demonstrated that sarA directly interacts with ica promoter and induces ica transcription. Real-time reverse transcription PCR studies showed a parallel reduction in the expression of $i c a A, \operatorname{sig} \beta$ and $s a r A$ and extracellular matrix production in SCVs of MRSA. This might be due to oxacillin that works as a stress factor responsible for induction of biofilm formation in MRSA isolates. This is proved in our previously published study. ${ }^{30}$ According to our hypothesis, oxacillin activates $\operatorname{sig} \beta$ and thereby affects the expression of sarA or ica that results in biofilm formation in wild-type MRSA isolates. Contrary to wild type, SCVs are metabolically inactive and do not respond to oxacillin, which is active against growing cells only. Therefore, stress-responsive genes, that is $\operatorname{sig} \beta$ and $\operatorname{sar} A$, are not induced. Conversely, MSSA isolates are natural biofilm producers that function without any in vitro induction or known factors. These unknown factors might be active against SCVs and responsible for the continuous sig $\beta$ and $\operatorname{sar} A$ gene expression, which results in ica-independent biofilm formation. In the present study, our findings have provided evidence for different mechanisms of biofilm development; it seems that the regulatory pathways controlling biofilm formation are different in MRSA and MSSA isolates.

\section{ACKNOWLEDGEMENTS}

We are thankful to Mr Yousf Khan, Laboratory Engineer, Central Research Laboratory, University of Karachi, for providing Scanning Electron Microscopy and RT-PCR facilities.

1 Costerton, W. et al. The application of biofilm science to the study and control of chronic bacterial infections. J. Clin. Invest. 112, 1466-1477 (2003).

2 Gotz, F. Staphylococcus and biofilms. Mol. Microbiol. 43, 1367-1378 (2000).

3 Parsek, M. R. \& Singh, P. K. Bacterial biofilms: an emerging link to disease pathogenesis. Annu. Rev. Microbiol. 57, 677-701 (2003).

4 Stoodley, P. et al. Direct demonstration of viable Staphylococcus aureus biofilms in an infected total joint arthroplasty. A case report. J. Bone Joint Surg. Am. 90, 1751-1758 (2008).

5 Yarwood, J. M., Paquette, K. M., Tikh, I. B., Volper, E. M. \& Greenberg, E. P. Generation of virulence factor variants in Staphylococcus aureus biofilms. J. Bacteriol. 189, 7961-7967 (2007)

6 Lewis, K. Persister cells, dormancy and infectious disease. Nat. Rev. Microbiol. 5, 48-56 (2007).

7 Lewis, K. Persister cells and the riddle of biofilm survival. Biochemistry (Mosc.) 70, 267-274 (2005)

8 Proctor, R. A., Balwit, J. M. \& Vesga, O. Variant sub-populations of Staphylococcus aureus as cause of persistent and recurrent infections. Infect. Agents Dis. 3, 302-312 (1994)

9 Higashi, J. M. \& Sullam, P. M. Staphylococcus aureus biofilms. In Biofilms Infection, and Antimicrobial Therapy (eds Pace, J. L., Rupp, M. E. \& Finch, R. G.) 81-108 (Taylor \& Francis, Boca Raton, FL, USA, 2006).

10 Gilot, P., Lina, G., Cochard, T. \& Poutrel, B. Analysis of the genetic variability of genes encoding the RNA III-activating components Agr and TRAP in a population of Staphylococcus aureus strains isolated from cows with mastitis. J. Clin. Microbiol. 40, 4060-4067 (2002) 
11 O'Neill, E. et al. Association between methicillin susceptibility and biofilm regulation in Staphylococcus aureus isolated from device related infections. J.Clin. Microbiol. 45, 1379-1388 (2007).

12 Valle, J. et al. SarA and not sig $\beta$ is essential for biofilm development by Staphylococcus aureus. Mol. Microbiol. 48, 1075-1087 (2003).

13 Mariana, N. S., Salman, S. A., Neela, V. \& Zamberi, S. Evaluation of modified Congo red agar for detection of biofilm produced by clinical isolates of methicillin resistance Staphylococcus aureus. Afr. J. Microbiol. Res. 3, 330-338 (2009).

14 Mirani, Z. A. \& Jamil, N. Effect of sub-lethal doses of vancomycin and oxacillin on biofilm formation by vancomycin intermediate resistant Staphylococcus aureus. J. Basic Microbiol. 51, 191-195 (2011).

15 Allegrucci, M. \& Sauer, K. Characterization of colony morphology variants isolated from Streptococcus pneumoniae biofilms. J. Bacteriol. 189, 2030-2038 (2007).

16 Bayston, R., Ashraf, W. \& Smith, T. Triclosan resistance in methicillin-resistant Staphylococcus aureus expressed as small colony variants: a novel mode of evasion of susceptibility to antiseptics. J. Antimicrob. Chemother. 59, 848-853 (2007).

17 Chen, X., Zhang, M., Zhou, C., Kallenbach, N. R. \& Ren, D. Control of bacterial persister cells by Trp/Arg-containing antimicrobial peptides. Appl. Environ. Microbiol. 77, 4878-4885 (2011).

18 Mahami, T., Adu-Gyamfi, A. \& Owulah, C. Comparative susceptibility of in vitro biofilm and planktonic cells of Staphylococcus aureus to antimicrobials. Afr. J. Microbiol. Res. 4, 1209-1214 (2010).

19 Merle, E. O., Douglas, W., Morck, K., Andre, G. \& Ronald, R. R. Biofilm bacteria: formation and comparative susceptibility to antibiotics. Can. J. Veter. Res. 66, 86-92 (2002).

20 Nuryastuti, T. et al. Effect of cinnamon oil on icaA expression and biofilm formation by Staphylococcus epidermidis. Appl. Environ. Microbiol. 75, 6850-6855 (2009).

21 Black, C. C. et al. The role of mecA and blaZ regulatory elements in mecA expression by regional clones of methicillin-resistant Staphylococcus pseudintermedius. Vet. Microbiol. 151, 345-353 (2011).

22 Chan, P. F., Foster, S. J., Ingham, E. \& Clements, M. O. The Staphylococcus aureus alternative sigma factor sigmaB controls the environmental stress response but not starvation survival or pathogenicity in a mouse abscess model. J. Bacteriol. 180, 6082-6089 (1998).

23 Tormo, M. A. et al. SarA is an essential positive regulator of Staphylococcus epidermidis biofilms. J. Bacteriol. 187, 2348-2356 (2005).

24 Shang, W., Davies, T. A., Flamm, R. K. \& Bush, K. Effects of ceftobiprole and oxacillin on mecA expression in methicillin-resistant Staphylococcus aureus clinical isolates. Antimicrob. Agents Chemother. 54, 956-959 (2010).
25 Xie, Y. et al. Genotypes and toxin gene profiles of Staphylococcus aureus clinical isolates from China. PLOS ONE 6, e28276 (2011).

26 Hall-Stoodley, L., Costerton, J. W. \& Stoodley, P. Bacterial biofilms: from the natural environment to infectious diseases. Nat. Rev. Microbiol. 2, 95-108 (2004).

27 Haaber, J., Cohn, M. T., Frees, D., Andersen, T. J. \& Ingmer, H. Planktonic aggregates of Staphylococcus aureus protect against common antibiotics.. PLOS ONE 7, e41075 (2012).

28 Lewis, K. Riddle of biofilm resistance. Antimicrob. Agents Chemother. 45, 999-1007 (2001).

29 Wingender, J. \& Flemming, H. C. Biofilms in drinking water and their role as reservoir for pathogens. Int. J. Hyg. Environ. Health 214, 417-423 (2011).

30 Mirani, Z. A. et al. Biofilm formation and dispersal of Staphylococcus aureus under the influence of oxacillin.. Microb. Pathog. 61-62, 66-72 (2013).

31 La Tourette Prosser, B., Taylor, D., Dix, B. A. \& Cleeland, R. Method of evaluating effects of antibiotics on bacterial biofilm. Antimicrob. Agents Chemother. 31, 1502-1506 (1987).

32 Singh, R., Ray, P., Das, A. \& Sharma, M. Role of persisters and small-colony variants in antibiotic resistance of planktonic and biofilm-associated Staphylococcus aureus: an in vitro study. J. Med. Microbiol. 58, 1067-1073 (2009).

33 Lewis, K. Persister cells. Annu. Rev. Microbiol. 64, 357-372 (2010).

34 Haussler, S. Biofilm formation by the small colony variant phenotype of Pseudomonas aeruginosa. Environ. Microbiol. 6, 546-551 (2004).

35 Latimer, J., Forbes, S. \& McBain, A. J. Attenuated virulence and biofilm formation in Staphylococcus aureus following sublethal exposure to triclosan. Antimicrob. Agents Chemother. 56, 3092-3100 (2012).

36 Beenken, K. E., Blevins, J. S. \& Smeltzer, M. S. Mutation of sarA in Staphylococcus aureus limits biofilm formation. Infect. Immun. 71, 4206-4211 (2003).

37 Rachid, S. et al. Alternative transcription factor $\mathrm{SB}$ is involved in regulation of biofilm expression in a Staphylococcus aureus mucosal isolate. J. Bacteriol. 182, 6824-6826 (2000).

38 Kiedrowski, M. R. et al. Nuclease modulates biofilm formation in communityassociated methicillin-resistant Staphylococcus aureus. PLOS ONE 6, e26714 (2011).

39 Mitchell, G. et al. A role for sigma factor B in the emergence of Staphylococcus aureus small-colony variants and elevated biofilm production resulting from an exposure to aminoglycosides. Microb. Pathog. 48, 18-27 (2010).

40 Lauderdale, K. J., Boles, B. R., Cheung, A. L. \& Horswill, A. R. Interconnections between Sigma B, agr, and proteolytic activity in Staphylococcus aureus biofilm maturation. Infect. Immun. 77, 1623-1635 (2009). 